\title{
Periodically collapsing bubbles in the South African stock market
}

\author{
Mehmet Balcilar ${ }^{\mathrm{a}, \mathrm{b}}$, Rangan Gupta ${ }^{\mathrm{b}}$, Charl Jooste ${ }^{\mathrm{b}}$, Mark E. Wohar ${ }^{\mathrm{c}, *}$ \\ a Department of Economics, Eastern Mediterranean University, Turkey \\ b Department of Economics, University of Pretoria, Pretoria, South Africa \\ c College of Business Administration, University of Nebraska at Omaha, USA
}

\begin{abstract}
:
This paper studies the existence and timing of bubbles in South Africa's stock market. An empirical model of bubble formation is tested against three competing models of asset price returns that rule out the existence of bubbles. The model controls for nonlinearities inherent in asset price returns by allowing for the existence of multiple regimes. The bubble model fits the data better than the competing models and suggests that the formation and existence of periodically collapsing bubbles are a reality.
\end{abstract}

Keywords:Bubbles, Regime switching, Collapse

\section{Introduction}

Research on stock market bubbles will continue to have relevance as long as market risk and policy concerns about the formation of asset prices and arbitrage opportunities exist. By now it is generally agreed that stock market shocks can have adverse consequences - and that the global repercussions are significant. Systemic stock market price shocks imply that actual returns to investment and financial stability are all interwoven in a complex financial system - present in both stock price commonalities in an existing market (Greenwood, 2005) and stock markets across countries (Engle et al. 1990). If bubbles exist and are in the process of growing, they are not only of interest to the investor and policy maker about their existence, but also the implications that bubbles would have if they were to burst. The study of bubbles is even more complex since it is not even generally agreed upon that bubbles even exist. In fact if economic agents are completely rational and forward looking the underlying price of the bubble is the fundamental price - i.e. bubbles cannot exist. The complication becomes more nuanced once one distinguishes between different kinds of bubbles such as credit fuelled bubbles or bubbles formed due to irrational behavior. There are many competing theories on the formation and existence of bubbles that are complicated - this means that the empirical tools to test and identify these theories are just as complicated.

South Africa is an interesting case study for bubbles. Its stock market index, the Johannesburg All Share Index (ALSI) yielded returns in excess of economic growth post financial crisis. Persistently weak economic growth suggests that stock returns should have been lower - assuming that economic growth is a reasonable proxy for fundamentals. Since real returns in the stock market are well above the fundamentals as implied from economic growth rates, it would be interesting to test whether it is due to a bubble. The reader should be aware that a significant proportion of these returns is due to

\footnotetext{
is We would like to thank Professor Chris Brooks for kindly providing us with the computer codes used in the empirical part of the analysis.

* Corresponding author.

E-mail addresses: mehmet@mbalcilar.net (M. Balcilar), rangan.gupta@up.ac.za (R. Gupta),Jooste.Charl@yahoo.co.za (C. Jooste), mwohar@unomaha.edu (M.E. Wohar).
} 
diversification strategies of companies that extend well into other countries, and hence it is possible for stock returns to be higher than economic growth.

The existence of an asset price bubble originates from the idea that price deviations from some fundamental price exist. This fundamental price is determined by rational behavior and is not always easy to measure. Various methodologies have attempted to empirically calculate the fundamental price and they range from statistical filters (Jordà et al., 2015) to identify large deviations (Borio and Lowe, 2002). However, rising asset prices do not always imply the formation of bubbles or irrational behavior. There exist many candidates for what seems to be higher than normal returns. Increased risk appetite changes the fundamental price of an underlying asset within the confines of rational expectations (Cambell and Cochrane, 1999). Conditional variance of fundamentals or uncertainty is also used to explain asset price fluctuations (Bansal and Yaron, 2004). Another candidate is the idea that sunspots cause permanent deviations from an equilibrium path - the selffulfilling outcome now becomes the new equilibrium. Fama ${ }^{1}$ essentially argues that large movements in asset prices can be described by time varying risk premia, while Shiller (2000) argues that psychological effects, which are often irrational, such as herd behavior can affect asset prices and lead to bubbles. A third possibility allows for increased risk appetite to fuel asset prices too, way above fundamental prices if stock positions are leveraged.

To distinguish between the competing theories in the extant literature we apply various stylized models to describe the changes in the Johannesburg All Share Index. The All Share Index is one of the most capitalised stock exchanges in the emerging market world, ${ }^{2}$ and has a long history of trading activity and has persistently outperformed the real domestic economy since the 2008/09 financial crisis - which makes it a good candidate to test for bubble behavior. In particular we model returns based on four models where one tests for periodically collapsing bubbles - the idea that bubbles can be persistent, but eventually collapses. All of the specifications tests allow for multiple regimes to distinguish periods of low vs. high stock market returns. The stock market's fundamental price provides an indication of whether observed prices are exhibiting a bubble behavior. The results in this paper can be used by investors and policy makers to study the occurrence of bubbles. Importantly, the study identifies the time-varying probability that a bubble survives or crashes.

In the past the formation of bubbles has been largely ignored by policy makers since the prevailing view was that monetary policy should focus on inflation and output stabilisation (Galì, 2014), a view no longer held by all (Svensson, 2014) given the sheer economic costs when bubbles do burst (Jordà et al., 2015). Unfortunately the policy advice is not always clear-cut, as Galì (2014) shows, "leaning against the wind" policies may inflate the bubble component while reducing the fundamental price (which is linked to the discounted value of the stream of profits).

We add to the South Africa literature by empirically testing for periodically collapsing speculative bubbles in a Markovswitching setup over the period of January 1954 to April 2015, where the returns of the ALSI is directly related to the size of the bubble and the regimes are identified as one where the bubble persists and survives for a finite period and one where it collapses. We employ an empirical model of bubble formation and compare it against three competing models of asset price returns that rule out the existence of bubbles. Our empirical model controls for nonlinearities inherent in asset price returns by allowing for the existence of multiple regimes. The bubble model fits the data better than the competing models and suggests that the formation and existence of periodically collapsing bubbles are a reality.

\section{Literature review}

South Africa's stock exchange is well-capitalised and one of the largest in emerging markets. The stock market returns since the 2008/09 financial crisis have exceeded economic growth. It is important to note that listed companies are well diversified with returns not always accruing domestically, but from foreign activity. An example includes one of South Africa's main telecommunication companies that operate across the African continent-MTN. For value investors the fundamental price of a stock is of great importance and provides an anchor to evaluate whether a share is over-bought or under-bought. Returns that are above an underlying fundamental value can be construed as excessive and are suggestive of the formation of a bubble. If a bubble exists, the next important piece of information is to understand when and/or whether it will burst and how big the correction will be?

A bubble in asset prices is defined as the part of asset price movements that is unexplainable by the mechanisms that drive the long term asset price in the relevant theoretical model (Flood and Garber, 1984; Blanchard and Watson, 1982). The variables that reflect these effects are called the fundamentals, and the long term forecast price derived within the context of a particular model of asset price determination on the basis of the fundamentals is the fundamental price. A significant deviation between it and the actual asset price is the bubble.

There is a long history of asset price research and the formation of bubbles. A recent BIS study highlights the real economic risks of bubbles that burst. Consumption patterns are tied to wealth. If wealth is perceived to be permanently higher than the life-cycle model of consumption, consumption would also be permanently higher. A long duration in an asset price bubble might create the illusion of permanently higher wealth and lead to unsustainable levels of consumptionthus making the link between financial market shocks and the real economy more concerning.

\footnotetext{
${ }^{1}$ http://www.npr.org/sections/money/2013/11/15/245251539/whats-a-bubble

2 http://www.african-exchanges.org/members/jse-ltd
} 
The underlying idea about the presence of bubbles concerns the fact that speculators and investors maintain a belief that, despite the stocks being overvalued with respect to its fundamentals, it is still profitable to buy additional units of it. Thus, a bubble acquires importance in driving the price of equities away from the equilibrium determined by its fundamentals because market agents perceive the presence of profit opportunity. In fact, movements of asset prices away from their fundamentals signal the occurrence of self-fulfilling prophecies of market participants, caused by events that are exogenous to the market. Essentially, the presence of bubbles in asset markets implies that market participants are not allocating their savings to the best possible investment. Furthermore, the analysis of rational bubbles, based on rational expectations, has an element of indeterminacy, which usually arises when the current decisions of agents depend both on the current market price and on their expectations of future prices (see Obstfeld and Rogoff, 1997). Given this, an obvious conclusion is that a single hypothesis cannot encompass sequences of prices as only one sequence is the market fundamental price path.

Such rational bubbles would, if it ever arose, have and explosive path, as shown in Blanchard (1979) and Blanchard and Watson (1982). This points out a basic difficulty that arises in testing for the existence of rational bubbles, as pointed out by Flood and Garber (1984): the contribution of hypothetical rational bubbles to asset prices would not be directly distinguishable from the contribution of market fundamentals that the researcher cannot observe.

Diba and Grossman (1984), propose an empirical strategy to deal with this problem, on the basis of stationarity tests for obtaining evidence against the existence of explosive rational bubbles. Diba and Grossman (1988a) implement such tests for explosive rational bubbles in stock prices using a model that assumes a constant discount rate, but allows unobservable variables to affect market fundamentals. Their results reject the occurrence of explosive rational bubbles in the stock market prices they analyze. However, Diba and Grossman (1988b) have shown that the impossibility of negative rational bubbles in stock prices implies theoretically that a bubble can never restart, if it ever collapses (i.e., falls to zero).

In empirical research, the main literature has followed three different methods of investigating the idea of bubbles driving asset prices away from their economic fundamentals equilibrium. The first is the variance bound test or volatility test, originally proposed by Shiller (1981) to study the volatility of long-term bonds. A second econometric method is based on the Hausman (1978) test and called the Hausman specification test. The specification test was originally published by West (1987) to investigate the presence of bubbles in the stock markets.

Evans (1986) proposes a nonparametric procedure that takes into account the possibility of occurrence of more than one bubble, each covering part of the sample period, and finds evidence of a negative bubble in the excess return to holding sterling rather than dollar assets during 1981-1984.

West (1987) proposes a parametric approach based on the Hausman specification test, and rejects the null hypothesis of no bubbles in the Standard and Poor's 500 index (1871-1980) and the Dow Jones index (1928-1978).

Diba and Grossman (1988a) propose testing the stock price and the dividend series for the presence unit roots, and for cointegration between them, to test for bubbles. They conclude that the empirical evidence is inconsistent with the existence of an explosive rational bubble in prices.

The explosive behavior of speculative bubbles implies that they would arise, grow, collapse, and definitively disappear. Since this does not appear to be an often observed behavior of asset prices, Blanchard (1979) proposes a model of periodically collapsing bubbles, whose state stochastically shifts between survival and collapse, with exogenous transition probabilities, and argues that this type of bubble can better mimic the behavior of the price of speculative assets. This idea has been further developed by Hamilton (1989) in a model that uses a Markov-switching regression to characterize the changes in the parameters of the autoregressive process, and displays nonlinear behavior when regime shifts occur. The estimation of his model is different from that of the Kalman filter, where the estimates of the unobserved continuous state vector are produced by a linear algorithm, because the filter and smoother he proposes yield nonlinear inference about a discrete-valued unobserved state vector.

Evans (1991) expanded on Hamilton's idea by proposing a model of rational bubbles that are always positive and periodically collapse to zero, but where a later resurgence of the bubble is allowed. He also allows the endogenous determination of the probability for the occurrence of the two regimes, and shows that the tests proposed by Diba and Grossman (1988a), and others, are unable to detect that important class of rational bubbles. The point is demonstrated by constructing rational bubbles that appear to be stationary when unit root tests are applied, even though they are explosive in a relevant sense. This points out to the difficulties of testing for rational bubbles in asset price processes that allow periodically collapsing bubbles, as is our case.

Evans (1991) is the standard reference for a bubble that collapses periodically and switches its growth regime, depending on its size. Whenever it exceeds a certain value, it enters a regime where a stochastic variable with a Bernoulli distribution shifts its local behavior between two trajectories: it can either grow faster, or can it collapse, reverting to a mean value. ${ }^{3}$

Van Norden and Schaller (1993) generalized Hamilton (1989) Hamilton's (1989) model and applied it to describe and analyze stock market returns, and find very strong evidence of switching behavior. Specifically, they provide an alternative specification of the periodically collapsing bubble, where the bubble regime is a non-observable stochastic binary variable whose probability of occurrence is a function of the bubble size. In addition to the different specification of the bubble, these

\footnotetext{
${ }^{3}$ Evans (1991) points out that, when applied to this type of bubble, the Diba and Grossman(1988b) unit root based test would lead to incorrect conclusions regarding the presence of a bubble. However, Charemza and Deadman (1995) later rejoin this discussion, and propose a unit root based test of explosive regime-switching bubbles.
} 
models display another crucial difference: in Evans (1991) the regime is observable, while in Van Norden and Schaller (1993) it is not. Since the relation between the innovation and the bubble size is determined by the regime, the latter's model allows for a more flexible interaction between them.

Van Norden and Schaller (1993) apply their model to the Toronto stock market index from January 1956 to November 1989, and find evidence of regime switches in stock market returns that are influenced by apparent deviations from fundamentals. Van Norden (1996) used this model to study the dynamics of speculative bubbles in the exchange rate between the US dollar and three other major currencies, and finds mixed evidence regarding the occurrence of regime-switching bubbles of that type. Several other studies test for the presence of regime-switching bubbles in a variety of data sets. For example, Funke et al. (1994) examine the inflation rate in Poland, Roche (2001) analyzes the price of land in Iowa, and Brooks and Katsaris (2005) study the S\&P 500, with this type of model. ${ }^{4}$

Van Norden (1996) extends the Van Norden and Schaller (1993) model to test for bubbles in the exchange rate. He implicitly uses the asset market approach to exchange rate determination (see, for example, Mussa, 1984) and views it as the relative price of the domestic assets in the two economies. The bubble is the misalignment of the exchange rate with respect to the fundamental rate, and its collapse is the correction of that "error". ${ }^{3}$ As in the earlier model, he specifies that the probability of survival of the bubble decreases with its size. Also, in his model the size of the innovation in the next period's exchange rate is a linear function of the bubble observed in the current period. To estimate the model, he loglinearizes the adjustment function, to obtain a stochastic specification with two linear regimes. It is important to note that, since the level of fundamental exchange rate in the reference year is given, its trajectory is exogenous to the model.

Numerous empirical studies have attempted to investigate the existence of rational bubbles in the foreign exchange market. However, results regarding the existence of rational bubbles have been mixed. ${ }^{5}$ In empirical studies on rational bubbles in asset prices, stationarity tests are first recommended by Hamilton and Whiteman (1985) and Diba and Grossman (1988a,b) as an indirect way to obtain evidence for rational bubbles. If asset prices are explosive while their fundamentals are non-explosive, it provides indirect evidence for existence of bubbles in asset prices. However, periodically collapsing bubbles cannot be detected by standard unit root and cointegration tests, as asset prices with periodically collapsing bubbles look very much like a unit root process (Evans, 1991).

The major difficulty of employing either the volatility test or the specification test is related to the fact that both methodologies depend strongly on the chosen model of exchange rate determination. Hence, the excess volatility observed in some studies may be caused by factors other than the presence of rational bubbles. In particular, for the specification test, Flood and Hodrick (1990) argue that the reliability of conclusions based on omitted variables may be weak since the monetary model in general produces misleading results. This may lead bubble tests towards rejection of the null hypothesis of no bubbles.

Bubble tests based on unit root tests and cointegration tests have, been potentially misleading in the presence of bubbles collapsing periodically. Evans (1991) was the first point out this kind of difficulty in examining bubbles using either unit root tests or cointegration tests. According to Evans the traditional cointegration tests leads to rejection of the null hypothesis of no bubbles more often than if the presence of a particular type of bubble was not taken into account. One argument that can be put forth is that unit root tests or cointegration tests, when faced with periodically collapsing rational bubbles may lead, with a high degree of probability, to a wrong conclusion that bubble components are non-existent in the stochastic process.

Another test procedure for periodically collapsing bubbles was carried out by Hall et al. (1999) which allowed for the pos-sibility of changes in the dynamic behavior of asset prices across the sample. In effect, the methodology proposed constitutes a generalization of the augmented Dickey-Fuller (ADF) unit root test applied to the class of Markov-switching regime models (see Hamilton, 1988,1989). An important difficulty is to identify collapsing periods from expanding ones. Hall et al. (1999) argue that the proposed methodology overcomes some of the econometric problems involved traditional unit root tests (see Evans, 1991). They applied the ADF-switching unit root test to investigate the presence of an explosive autoregressive root to the hyperinflation process in Argentina during the 1980s. The results suggested that during that time it was possible to observe a clear explosive regime in the consumer price index associated with the rapid growth in the money supply. The implication was that the 1989 hyperinflation in Argentina was related to adverse fundamental behavior, and not to rational bubbles.

Using a recursive method, a supremum ADF (SADF) bubble test was proposed by Phillips et al. (2011), which can detect exuberance in asset price series during an inflationary phase. However, the Phillips et al. (2011) recursive method is especially effective when there is a single bubble episode in the sample data, for instance, the 1990s NASDAQ crash analyzed in Phillips et al. (2011), and U.S. house price bubble in 2006-2007 analyzed in Phillips and Yu (2011). Therefore, given the possibility of multiple bubbles within the same sample period, Phillips et al. (2015) developed the generalized sup ADF (GSADF) test. The major advantage of the approach is that it allows one to account for the nonlinear structure and break

\footnotetext{
${ }^{4}$ A related body of literature employs switching models with Markovian state dependence (Hamilton, 1994). This type of regime switching is not considered in the models mentioned above, and substantially complicates the estimation because it requires the use of more than two states, as indicated by Evans (1996).

${ }^{5}$ Meese (1986) provides significant evidence in support of the bubble hypothesis by applying the Hausman (1978) specification test. In contrast, West (1987) applies the volatility test and finds no evidence of bubbles. Wu (1995) also rejects the existence of bubbles in the foreign exchange rate using state space analysis.
} 
mechanisms while investigating the existence of multiple bubbles. Other break testing procedures such as Chow tests, model selection, and CUSUM tests have also been applied for dating bubbles (see for example, for a detailed review in this regard Homm and Breitung, 2012, and Breitung and Kruse, 2013). Balcilar et al. (2015), on the other hand relies on long-memory test with breaks to identify housing bubbles in the US over the annual period of 1831-2013. In addition, "econophysics" based approaches have also been used to detect bubbles (both positive and negative) as in the recent work by Zhang et al. (2016) to analyze bubbles in the monthly S\&P 500 covering the period from 1791:08 to 2014:08.

Some of these models, especially the ones based on unit root and long-memory type approaches, have a restrictive feature which may be undesirable in some contexts: they assume that the bubble increases indefinitely until some exogenous structural change occurs. This limitation can be removed by specifying a regime-switching model for the bubble, which can be appropriate if agents contemplate the existence of two alternative dynamics of the bubble size, and incorporate the possibility of a regime change in their expectations. In this formulation, the bubble is either: (i) collapsing, and its expected size is decreasing, or (ii) it survives, and its expected size is increasing. Some examples of this approach, which is also followed in the model proposed here, are discussed below.

At this stage, it is important to lay out the literature on bubbles testing in South Africa. While, Das et al. (2011) using the SADF test detected bubbles in the aggregate South African housing market, Chang et al. (forthcoming a), based on nonlinear panel unit root tests on provincial house prices did not find the same. As far as stock price is concerned, Chang et al. (forthcoming b) used the GSADF test on the South African stock market (besides, Brazil, Russia, India and China), and identified 2005-2006 as a period of irrational exuberance. Against this backdrop, our paper aims to extend the work by Chang et al. (forthcoming b) by: (i) considering a longer sample, hence possibly more episodes of bubbles in the South African stock market history, covering the period of January 1954 to April 2015 compared to the period of June 1995 to February 2013, and; (ii) more importantly, we make a methodological contribution by applying a Markov-Switching approach, which is preferred over the GSADF test because it allows stochastic bubbles, less prone to model identification, such as the lag order selection and determination of window size, and partially collapsing bubbles. Additionally, the Markov switching approach has the feature that the probability of the collapse of the bubble to depend on the size of the bubble and therefore the switches in the bubble regimes are predictable from the previous information.

\section{Methodology}

Following Nneji et al. (2013) the regime switching model for bubbles in the equity market starts off with the basic asset pricing theory in which the price of an asset $\left(P_{t}^{a}\right)$ is equal to its expected price and some payoff function (in this case dividends) (Lucas, 1978; Cochrane, 2005):

$$
P_{t}^{a}=E_{t}\left[\beta \frac{U^{\prime}\left(C_{t+1}\right)}{U^{\prime}\left(C_{t}\right)} X_{t+1}\right] \rightarrow P_{t}^{a}=E_{t}\left[M_{t+1} X_{t+1}\right]
$$

where $X_{t+1}$ is a random variable and represents the payoff function. $\beta \frac{U^{\prime}\left(C_{t+1}\right)}{U^{\prime}\left(C_{t}\right)}$ is a stochastic discount factor derived from the household's intertemporal consumption first order condition. For the stock market $X_{t+1}=P_{t+1}+D_{t+1}$ while $\beta \frac{U^{\prime}\left(C_{t+1}\right)}{U^{\prime}\left(C_{t}\right)} \approx \frac{1}{1+i_{t}}$. We write Eq. (1) as:

$$
P_{t}^{a}=\frac{E_{t} P_{t+1}^{a}+D_{t+1}}{1+i_{t}}
$$

The fundamental price of the asset, i.e. the price of the asset determined by market fundamentals is the discounted value of all future dividend streams:

$$
P_{t}^{f}=\sum_{n=1}^{\infty} \frac{E_{t}\left(D_{t+n}\right)}{\left(1+i_{t}\right)^{n}}
$$

Deviations between the actual asset price and fundamental price is ascribed to a bubble $(B)$ and innovations in fundamental and non-fundamental values which are assumed to be normally distributed $u \sim N\left(0, \sigma^{2}\right)$ :

$$
B_{t}=P_{t}^{a}-P_{t}^{f}-u_{t}
$$

To obtain empirical values of the fundamental price Van Norden and Schaller (1993) argue that it is equal to the average price-dividend ratio multiplied by the dividend in a given period:

$$
P_{t}^{f}=\frac{\bar{P}}{\bar{D}} D_{t}
$$

Blanchard (1979) and Blanchard and Watson (1982) assume that bubbles grow exponentially and have a survival probability $q$ and a collapse probability $1-q$. In their model if a bubble does not collapse it is expected to grow in excess of the real rate of return. If the bubble collapses the price of an asset simply equals the fundamental price. In this model, there are 
no regeneration cycles. Van Norden and Schaller (1993) and Van Norden (1996) extend Blanchard and Watson (1982) by introducing a constraint in the bubble survivals, which depend on the relative size of the bubble:

$$
b_{t}=\frac{B_{t}}{P_{t}}
$$

The probability of being in a survival state thus falls with the relative size of the bubble $\left(\frac{\partial q\left(b_{t}\right)}{\partial\left|b_{t}\right|}<0\right)$. An important addition to the Blanchard and Watson (1982) model is that Van Norden and Schaller (1993) introduces partial collapses where bubbles are a function of a continuous and differentiable function $\left(0<\frac{\partial u\left(b_{t}\right)}{\partial b_{t}}<1\right)$. Their model for bubble survivals $(S)$ and bubble collapses $(C)$ can be summarised as:

$$
\begin{aligned}
& E_{t}\left(B_{t+1} \mid S\right)=\frac{1+i_{t}}{q\left(b_{t}\right)} B_{t}-\frac{1-q\left(b_{t}\right)}{q\left(b_{t}\right)} u\left(b_{t}\right) P_{t}^{a} \text { with probability } q\left(b_{t}\right) \\
& E_{t}\left(B_{t+1} \mid C\right)=u\left(b_{t}\right) P_{t}^{a} \text { with probability } 1-q\left(b_{t}\right)
\end{aligned}
$$

Van Norden and Schaller (1993) use the model to study bubbles. They assume that the return of an underlying asset can be formulated as:

$$
\begin{aligned}
& E_{t}\left(R_{t+1} \mid S\right)=M\left(1-b_{t}\right)+\frac{M b_{t}}{q\left(b_{t}\right)}-\frac{1-q\left(b_{t}\right)}{q\left(b_{t}\right)} u\left(b_{t}\right) \text { with probability } q\left(b_{t}\right) \\
& E_{t}\left(R_{t+1} \mid C\right)=M\left(1-b_{t}\right)+u\left(b_{t}\right) \text { with probability } 1-q\left(b_{t}\right)
\end{aligned}
$$

Thus the return of asset $M$ depends on regime of the previous period. The empirical model (after linearizing the model) is specified as:

$$
\begin{aligned}
& R_{t}^{s}=\beta_{s, 0}+\beta_{s, 1} b_{t}+u_{s, t+1} \\
& R_{t}^{c}=\beta_{c, 0}+\beta_{c, 1} b_{t}+u_{c, t+1} \\
& P\left(R_{t+1} \mid S\right)=q\left(b_{t}\right)=\phi\left(\beta_{q, 0}+\beta_{q, 1}\left|b_{t}\right|\right)
\end{aligned}
$$

$\phi$ is the standard cumulative normal distribution function and $\phi\left(\beta_{q, 0}\right)$ is the probability of being in the survival regime conditional that the bubble size equals zero, while $\phi\left(\beta_{q, 1}\right)$ shows how the probability of being in the survival regime changes with the relative size of the bubble. The unexpected returns of the surviving and collapsing bubbles are given by $u_{s, t+1}$ and $u_{c, t+1}$, respectively with a constant variance and zero mean.

The parameters are estimated by maximizing the following log-likelihood function:

$$
L\left(R_{t+1} \mid \Omega\right)=\sum_{t=1}^{T} \ln \left[P\left(R_{t+1} \mid S\right) \frac{\phi\left(\frac{R_{t}^{s}-\beta_{s, 0}+\beta_{s, 1} b_{t}}{\sigma^{s}}\right)}{\sigma^{S}}+\left(1-P\left(R_{t+1} \mid S\right)\right) \frac{\phi\left(\frac{R_{t}^{c}-\beta_{c, 0}+\beta_{c, 1} b_{t}}{\sigma^{c}}\right)}{\sigma^{c}}\right]
$$

$\Omega=\left\{\sigma^{s}, \sigma^{c}, \beta_{s, 0}, \beta_{s, 1}, \beta_{c, 0}, \beta_{c, 1}, \beta_{q, 0}, \beta_{q, 1}\right\}$ denote the parameters. For collapsing bubbles to be present the following conditions should hold: $\beta_{c, 0} \neq \beta_{s, 0} ; \beta_{c, 1}<0$ implying that the return of an asset is negative in a collapsing bubble regime; $\beta_{s, 1}>\beta_{c, 1}$ implying that the return in the surviving bubble regime is greater than in the collapsing regime and $\beta_{q, 1}<0$ which means that the probability of the bubble surviving decreases as the bubble size increases.

The model is tested against three alternative models to rule out specification errors:

1. The mixture-normal model of Akgiray and Booth (1988) where stock returns are modelled as a mixture of two normal distributions, i.e. assuming that errors do not vary across regimes $\left.\beta_{s, 1}=\beta_{q, 1}=\beta_{c, 1}=0\right)$ ).Or :

$$
R_{t+1} \sim N\left(\beta_{s, 0}, \sigma^{s}\right)
$$

with probability $q$ and $R_{t+1} \sim N\left(\beta_{c, 0}, \sigma^{c}\right)$ with probability $1-q$.

2. The fads model of Cutler et al. (1991) assumes that average returns are constant across regimes $\left(\beta_{s, 0}=\beta_{c, 0}=\beta_{0} ; \beta_{s, 1}=\right.$ $\beta_{c, 1}=\beta_{1}$ and $\left.\beta_{q, 1}=0\right)$. The model can be expressed as:

$$
R_{t+1}=\beta_{0}+\beta_{1} b_{t}+u_{t+1}
$$

where $u_{t+1} \sim N\left(0, \sigma^{s}\right)$ with probability $q$ and $u_{t+1} \sim N\left(0, \sigma^{c}\right)$ with probability $1-q$.

3. The regime volatility model of Schwert (1989b) where returns switch only as a result of volatility i.e. $\beta_{s, 0}=\beta_{s, 1}=$ $\left.\beta_{c, 0}=\beta_{c, 1}=0\right)$. Or:

$$
R_{t+1}=\beta_{0}+u_{t+1}
$$

where $u_{t+1} \sim N\left(0, \sigma^{s}\right)$ with probability $q$ and $u_{t+1} \sim N\left(0, \sigma^{c}\right)$ with probability $1-q$. 
Table 1

Descriptive Statistics.

\begin{tabular}{|c|c|c|c|c|c|c|}
\hline & Price & Dividends & Price/Dividend Ratio & Actual Returns & Fundamental Price & Relative Size of the Bubble \\
\hline Mean & 928.8612 & 3.7843 & 304.7515 & 0.0069 & 338.6811 & 0.4133 \\
\hline S.D. & 959.083 & 1.2318 & 335.4279 & 0.0618 & 251.78 & 0.3876 \\
\hline Min & 77.551 & 1.85 & 14.7998 & -0.2919 & 68.017 & -1.1578 \\
\hline Max & 4146.3 & 8.19 & 1552.9213 & 0.2477 & 1242.4 & 0.8495 \\
\hline Skewness & 1.45 & 0.9028 & 1.3661 & -0.5116 & 1.1916 & -1.443 \\
\hline Kurtosis & 1.1477 & 0.6172 & 0.9778 & 2.2402 & 0.6133 & 2.1542 \\
\hline JB & $300.1440^{* * *}$ & $112.4410^{* * *}$ & $259.8440^{* * *}$ & $188.0990^{* * *}$ & $186.8090^{* * *}$ & $400.6420^{* * *}$ \\
\hline $\mathrm{Q}(1)$ & $722.8849^{* * *}$ & $706.2712^{* * *}$ & $710.9848^{* * *}$ & $39.1854^{* * *}$ & $722.2756^{* * *}$ & $714.5692^{* * *}$ \\
\hline $\mathrm{Q}(4)$ & $2799.3803^{* * *}$ & $2595.8622^{* * *}$ & $2684.1401^{* * *}$ & $40.4849^{* * *}$ & $2785.4731^{* * *}$ & $2662.3202^{* * *}$ \\
\hline $\mathrm{ARCH}(1)$ & $720.8972^{* * * *}$ & $685.0266^{* * *}$ & $683.9049^{* * *}$ & $29.5948^{* * *}$ & $683.2716^{* * *}$ & $682.1017^{* * *}$ \\
\hline $\mathrm{ARCH}(4)$ & $718.0278^{* * *}$ & $683.7948^{* * * *}$ & $681.3540^{* * *}$ & $39.4343^{* * *}$ & $681.9549^{* * *}$ & $681.3583^{* * *}$ \\
\hline
\end{tabular}

${ }^{* * *}$ Represents significance at the $1 \%$ level.

Table 2

Estimates of the Van Norden and Schaller (1993, VNS) Speculative MS-Bubble Model.

\begin{tabular}{|c|c|c|c|c|}
\hline Coefficients & Estimate & S.E. & $t$-statistic & $p$-value \\
\hline$\beta_{s, 0}$ & $1.0494^{* * *}$ & 0.0046 & 227.2600 & $<0.0001$ \\
\hline$\beta_{s, 1}$ & $-0.0345^{* *}$ & 0.0192 & -1.7914 & 0.0368 \\
\hline$\beta_{c, 0}$ & $1.0281^{* * *}$ & 0.0049 & 208.2500 & $<0.0001$ \\
\hline$\beta_{c, 1}$ & $-0.0303^{* *}$ & 0.0154 & -1.9692 & 0.0247 \\
\hline$\beta_{q, 0}$ & $0.3881^{*}$ & 0.2398 & 1.6187 & 0.0530 \\
\hline$\beta_{q, 1}$ & $-2.1218^{* * *}$ & 0.8638 & -2.4563 & 0.0071 \\
\hline$\sigma_{s}$ & $0.0187^{* * *}$ & 0.0029 & 6.4672 & $<0.0001$ \\
\hline \multirow[t]{3}{*}{$\sigma_{c}$} & $0.0713^{* * *}$ & 0.0102 & 7.0162 & $<0.0001$ \\
\hline & $\log L$ & AIC & $\mathrm{BIC}$ & HQ \\
\hline & 1052.2000 & -2.8375 & -2.7875 & -2.8182 \\
\hline \multicolumn{5}{|c|}{ Likelihood ratio tests of restrictions } \\
\hline & LR statistic & $p$-value & & \\
\hline$\beta_{s, 0} \neq \beta_{c, 0}$ & $13.5950^{* * *}$ & 0.0002 & & \\
\hline$\beta_{c, 1}<0$ & $11.5860^{* * *}$ & 0.0007 & & \\
\hline$\beta_{s, 1}>\beta_{c, 1}$ & 0.1016 & 0.7500 & & \\
\hline$\beta_{q, 1}<0$ & $23.6520^{* * * *}$ & $<0.0001$ & & \\
\hline \multicolumn{5}{|c|}{ Bubble model misspecification test against stylized alternative models } \\
\hline & LR statistic & $p$-value & & \\
\hline Volatility regime & $134.5500^{* * *}$ & $<0.0001$ & & \\
\hline Mixture-normal & $74.5190^{* * *}$ & $<0.0001$ & & \\
\hline Fads & $37.8450^{* * *}$ & $<0.0001$ & & \\
\hline
\end{tabular}

Notes: The table reports estimates, coefficient restrictions tests, and misspecifications tests for the Van Norden and Schaller (1993, 1999) speculative MSBubble (VNS) model given in Eqs. (7)-(9). In the table S.E. denotes the standard error of the parameter estimate. AIC, BIC, and HQ stand for the Akaike, Bayesian, and Hannan-Quinn information criterion, respectively. $\log L$ represents the value of the log likelihood function and "<" signifies "less than".

\section{Results}

The sample period covers 736 observations over the period January 1954 to April 2015, with the data sourced from the Global Financial Database. Descriptive statistics are reported in Table 1 using the JSE All Shares Price Index (JSE ALSI), Dividends, Dividends/Price ratio, Actual JSE All Shares Index Returns, the fundamental price (Eq. (5)) and the Relative Size of the Bubble (Eq. (6)). In addition to the mean, standard deviation (S.D.), minimum (min), maximum (max), skewness, and kurtosis statistics, Table 1 also reports the Jarque-Berra normality test (JB), the Ljung-Box first $[Q(1)]$ and the fourth $[Q(4]$ autocorrelation tests, and the first $[\mathrm{ARCH}(1)]$ and the fourth $[\mathrm{ARCH}(4)]$ order Lagrange multiplier (LM) tests for the autoregressive conditional heteroskedasticity (ARCH).

There are already a few noticeable characteristics of the JSE from Table 1 . The fundamental price has on average been considerably less than the actual price. This leaves innovations in both the fundamental and bubble price as well as the actual bubble to explain the rest of the movements in the JSE ALSI. The average size of bubbles relative to the fundamental price is roughly less than a half. There were periods when collapses well exceeded the fundamental price. Interestingly, surviving bubbles have never exceeded the fundamental price. This points to possible asymmetries in asset price formation - providing us with an additional justification for our nonlinear specification. The nonlinear motivation is similarly supported by the Jarque-Berra test statistics where none of the prices nor returns have a normal distribution. In addition to the non-normal distribution we note the presence of both serial correlation and heteroscedasticity in the data.

The estimates for Eqs. (7) and (8) are provided in Table 2. All the coefficients are significant at the $10 \%$ level. The likelihood ratio tests imply that the first regime is the speculative bubble where the bubble continues to grow and survives while the 
Table 3

Estimates of the Mixture-Normal Model.

\begin{tabular}{|c|c|c|c|c|}
\hline Coefficients & Estimate & S.E. & $t$-statistic & $p$-value \\
\hline$\beta_{s, 0}$ & $0.9999^{* * *}$ & 0.0031 & 326.4000 & $<0.0001$ \\
\hline$\beta_{c, 0}$ & $1.0354^{* * *}$ & 0.0046 & 223.4200 & $<0.0001$ \\
\hline$\beta_{q, 0}$ & $-0.2513^{* * *}$ & 0.0287 & -8.7493 & $<0.0001$ \\
\hline$\sigma_{s}$ & $0.0842^{* * *}$ & 0.0039 & 21.5110 & $<0.0001$ \\
\hline \multirow[t]{3}{*}{$\sigma_{c}$} & $0.0391^{* * *}$ & 0.0040 & 9.8620 & $<0.0001$ \\
\hline & $\log L$ & AIC & $\mathrm{BIC}$ & HQ \\
\hline & 1014.9000 & -2.7444 & -2.7131 & -2.7323 \\
\hline \multicolumn{5}{|c|}{ Mixture-normal model misspecification test against the volatility regime model } \\
\hline & LR statistic & $p$-value & & \\
\hline Volatility regime & $60.0300^{* * *}$ & $<0.0001$ & & \\
\hline
\end{tabular}

Notes: The table reports estimates and misspecifications tests for the Akgiray and Booth (1988) normal-mixture model given in Eq. (10). In the table S.E. denotes the standard error of the parameter estimate. AIC, BIC, and HQ stand for the Akaike, Bayesian, and Hannan-Quinn information criterion, respectively. $\log L$ represents the value of the $\log$ likelihood function and "<" signifies "less than".

Table 4

Estimates of the Fads Model.

\begin{tabular}{|c|c|c|c|c|}
\hline Coefficients & Estimate & S.E. & t-statistic & $p$-value \\
\hline$\beta_{0}$ & $1.0418^{* * *}$ & 0.0030 & 350.0200 & $<0.0001$ \\
\hline$\beta_{1}$ & $-0.0394^{* * *}$ & 0.0053 & -7.4233 & $<0.0001$ \\
\hline$\beta_{q, 0}$ & -0.1537 & 0.8035 & -0.1913 & 0.4242 \\
\hline$\sigma_{s}$ & $0.0854^{* * *}$ & 0.0164 & 5.2005 & $<0.0001$ \\
\hline \multirow[t]{3}{*}{$\sigma_{c}$} & $0.0347^{* * *}$ & 0.0036 & 9.7035 & $<0.0001$ \\
\hline & $\log L$ & AIC & $\mathrm{BIC}$ & HQ \\
\hline & 1033.3000 & -2.7942 & -2.7629 & -2.7821 \\
\hline \multicolumn{5}{|c|}{ Fads model misspecification test against the volatility regime model } \\
\hline & LR statistic & $p$-value & & \\
\hline Volatility regime & $96.7040^{* * *}$ & $<0.0001$ & & \\
\hline
\end{tabular}

Notes: The table reports estimates and misspecifications tests for the Cutler et al. (1991) fads model given in Eq. (11). In the table S.E. denotes the standard error of the parameter estimate. AIC, BIC, and HQ stand for the Akaike, Bayesian, and Hannan-Quinn information criterion, respectively. log $L$ represents the value of the log likelihood function and "<" signifies "less than".

second regime is the collapsing bubble regime where prices falls. The average returns of the surviving bubble $\left(\beta_{s, 0}\right)$ is larger than the return of the collapsing $\left(\beta_{c, 0}\right)$.

Note that some of the other conditions that identify the speculative bubble are also met. The estimate of the relative size of the bubble in the collapsing regime is negative $\left(\beta_{c, 0}<0\right)$, while the probability of the bubble surviving decreases as the size of the bubble increases. Also note that the returns of the bubble in the collapsing regime are considerably more volatile than the returns in the surviving bubble, which point to the possibility of regeneration cycles. It is worthwhile to note that the returns in the surviving bubble also decreases as the size of the bubble increases. This is an important indicator which might help distinguish between the fundamental price of an asset and the bubble price of an asset - and may also be an indication of how soon the bubble is set to burst. These results hold under the likelihood ratio tests beneath Table 2 . All the conditions are met for the existence of periodically collapsing speculative bubbles. The various likelihood based tests also suggest that the Van Norden and Schaller (1993) bubble model provides a better explanation for returns than competing models.

The alternative models are presented in Tables 3-5. The Akgiray and Booth (1988) model attempts to rule out that returns are related to deviations of the stock price to its fundamental price, but that returns are simply a mixture of two normal distributions with the implication that only the means and variances of returns differ in each regime and not the error - in essence returns simply fluctuate without being considered a bubble. Two regimes, however, are identified. The results from Table 3 in contrast to the bubble model, suggest that volatility during the low-return regime (0.0391) is smaller than the volatility during the high-return regime $(0.0842)$. Despite statistically significant coefficients, the mean returns are higher (only marginally) in the second (collapsing) regime.

The fads model (Table 4) assumes that returns are constant across regimes, as well as proportional to the relative size of the bubble. Only the error regime switches between different states. The results of this model imply that returns are negatively related to the relative size of the bubble. Such a model would rule out herd behavior (irrational investment decisions) since an increase in a bubble would immediate be self-correcting as given by the negative coefficient.

The volatility regime model also assumes that returns are constant across regimes. The model, however, identifies to regimes - a high and low volatility regime.

It is important to note that the Van Norden and Schaller (1993) bubble model outperforms the other model versions empirically. For South Africa's stock market, it would seem reasonable to suggest that bubbles do periodically appear and 
Table 5

Estimates of the Volatility Regime Model.

\begin{tabular}{lllll}
\hline Coefficients & Estimate & S.E. & t-statistic & $p$-value \\
\hline$\beta_{0}$ & $1.0233^{* * *}$ & 0.0027 & 384.2300 & $<0.0001$ \\
$\beta_{q, 0}$ & $1.8787^{* *}$ & 0.8121 & 2.3134 & 0.0105 \\
$\sigma_{s}$ & $0.0570^{* * *}$ & 0.0055 & 10.3180 & 0.0001 \\
$\sigma_{c}$ & $0.2783^{*}$ & 0.1774 & 1.5689 & 0.0586 \\
& $\log L$ & AIC & BIC & HQ \\
& 984.9100 & -2.6655 & -2.6405 & -2.6559 \\
\hline
\end{tabular}

Notes: The table reports estimates for the Schwert (1989a) volatility regime model given in Eq. (12). In the table S.E. denotes the standard error of the parameter estimate. AIC, BIC, and HQ stand for the Akaike, Bayesian, and Hannan-Quinn information criterion, respectively. $\log L$ represents the value of the log likelihood function and "<" signifies "less than".

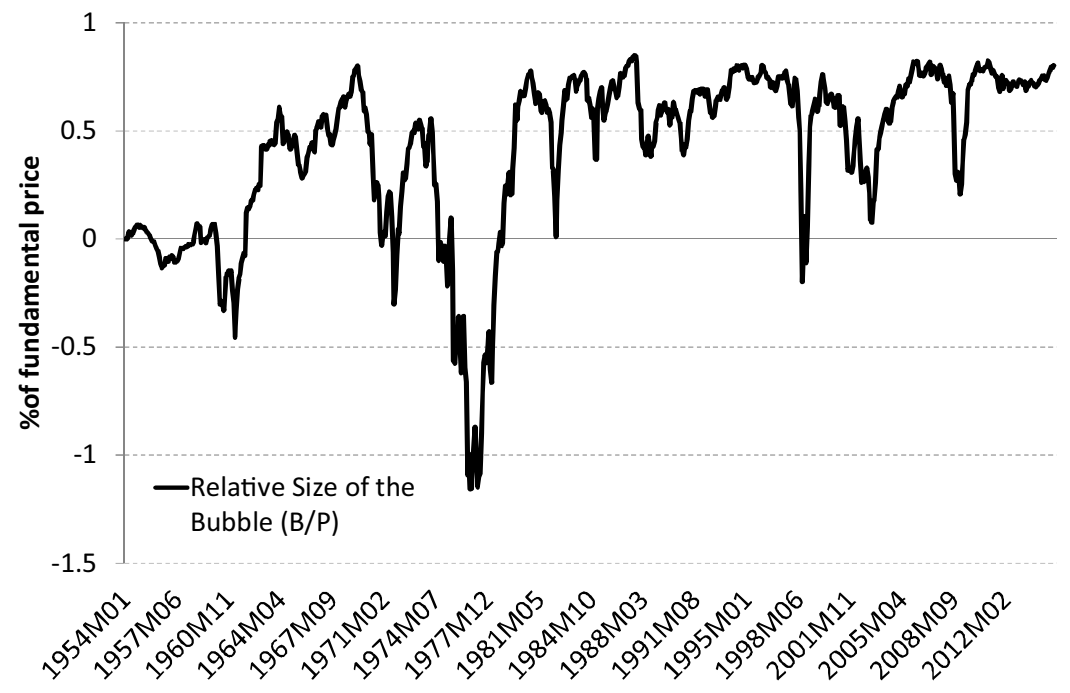

Fig. 1. The relative size of the stock exchange bubble (B/P).

Note: Refer to Eq. (6) defining the relative size of the bubble (B/P).

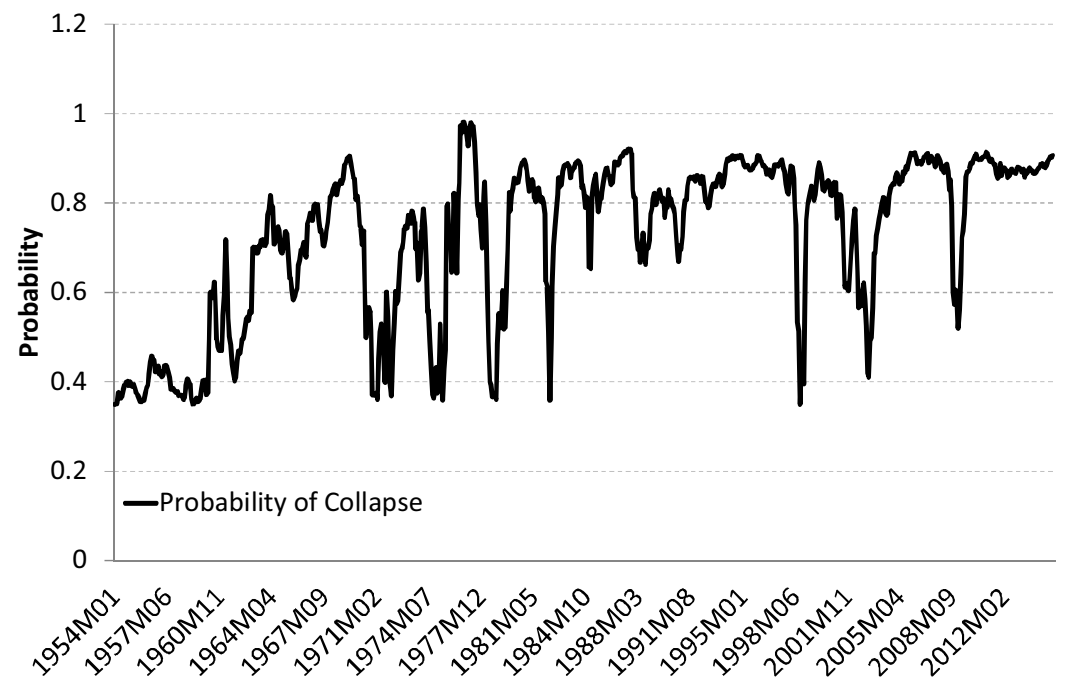

Fig. 2. The probability of a collapsing bubble.

burst. The statistically significant coefficients of the other models should still be considered seriously and hence the bubble formation model should not necessarily be taken as a given.

From Figs. 1 and 2 the probability of a collapsing bubble is clearly associated with the relative size of the bubble. Noting that in the early years up until the current period, mining companies contributed a significant share to the market capitalization in the JSE. As an example, the collapse (see Figs. 1 and 2) in 1971 matches the end of the gold standard. The 
collapse in 1977 is associated with arms embargo passed on to South African by the United Nations (Security Council Resolution 418). The Russian Rubble crisis had a world-wide impact with the systemic shocks reaching South Africa too. The 2008/09 financial crisis meant that the relative size of the bubble decreased in relation to the fundamental price. This implies that domestic and international events at any point in time can leads to a reversal in bubbles - which might have an endogenous adverse impact on the fundamental price too.

The probability of a collapse has increased since the financial crisis and has remained above $80 \%$. Considering that the data shows strong autocorrelation effects it is hardly surprising that the bubble size has remained elevated over a long period (2010-2015) period (see Hassan (2013) - “. . JSE prices can deviate from fundamentals, but profiting from such deviations requires facing the risk that the mispricing might persist and/or increase over the trading horizon”. This also reminds us of the bubble build-up in the housing market just before the crisis.

In the Van Norden and Schaller (1993) bubble model, date stamping of the bubbles would be probabilistic, since the model itself is probabilistic in nature. A significant rise in the probability of collapse would imply the end of a bubble, so based on that we can date the following periods as possible bubbles: 1960-1961, 1970-1971, 1974-1978, 1982, 1985, 1987, 1998, 2001, 2003, and 2008. Since, Chang et al. (forthcoming b) performed the GSADF test to date the South African bubbles, it makes sense to provide a comparison with our approach in this paper. The GSADF test statistic of the price-dividend ratio, based on a recursive estimation with the first 10 percent of the sample used for the first estimation, is plotted in Fig. A1 of the Appendix. As can be seen, unlike Chang et al. (forthcoming b), now the GSADF test on the longer sample detects a bubble only over the period of 1964 (January to May) and 1969 (January to June). Recall, Chang et al. (forthcoming b) had detected a bubble for the period of 2006-2007, which is now no longer picked up by the GSADF test.

\section{Conclusion}

Some evidence points to the formation and existence of speculative bubbles in the South African stock exchange market as given by the Johannesburg All Share Index. Periods of seemingly excessive returns, relative to returns tied to fundamentals, and significant slowdowns can be related to the formation of bubbles. Three stylized or alternative models of stock price returns are tested against a model of periodically collapsing bubbles. The bubble model used in this paper outperforms other stylized models of stock price determination-suggesting that excessive returns, relative to returns that are linked to fundamentals, arise due to either leveraged positions or irrational investor behavior. While the model helps to identify bubbles in probabilistic terms it does not indicate what behavior, credit fuelled or herding behavior, has led to its formation. Thus, the current paper only helps policy makers and investors identify bubbles, but refrain from prescribing how to manage, if at all, the formation of bubbles in South Africa. A further study might provide more insights into this matter.

\section{Appendix A.}

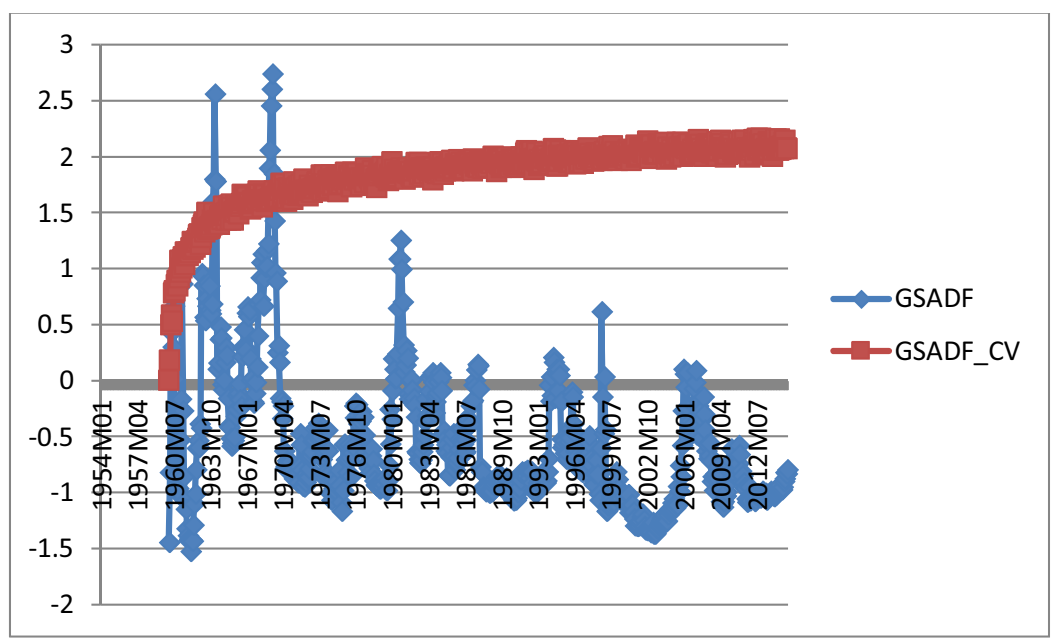

Fig. A1. GSADF Statistic of the Price-Dividend Ratio. 


\section{References}

Akgiray, V., Booth, G.G., 1988. Mixed diffusion-jump process modelling of exchange rate movements. Rev. Econ. Stat. $70,631-637$.

Balcilar, M., Katzke, N., Gupta, R., 2015. Identifying Periods of US Housing Market Explosivity. Department of Economics, University of Pretoria (Working Paper No. 201544).

Bansal, Yaron, 2004. Risks for the long run: a potential resolution of asset pricing puzzles. J. Finance 59 (4), 1481-1509.

Blanchard, O., Watson, M., 1982. Bubbles, rational expectations and financial markets. In: Wachtel, P. (Ed.), Crises in the Economic and Financial Structure. D.C. Heath and Company, Lexington, MA, pp. 295-316.

Blanchard, O., 1979. 'Speculative bubbles, crashes and rational expectations'. Econ. Lett. 3, 387-389.

Breitung, J., Kruse, R., 2013. When bubbles burst: econometric tests based on structural breaks. Stat. Papers 54 (4), 911-930.

Cambell, Cochrane, 1999. 'By force of habit: a consumption based explanation of aggregate stock market behavior'. J. Political Econ. $107,205-251$.

Chang, T., Liu, W.-C., Aye, G.C., Gupta, R., 2016a. Are there housing bubbles in South Africa? Evidence from SPSM-Based panel KSS test with a fourier function. Global Business Econ. Rev. (Forthcoming a).

Chang, T., Ranjbar, O., Gil-Alana, L., Aye, G.C., Gupta, R., 2016b. Testing for multiple bubbles in the BRICS stock markets. J. Econ. Stud. (Forthcoming b).

Charemza, W.W., Deadman, D.F., 1995. Speculative bubbles with stochastic explosive roots: the failure of unit root testing. J. Empir. Finance 2, $153-163$.

Cochrane, J.H., 2005. Asset Pricing. Princeton University Press, New Jersey.

Cutler, D.M., Poterba, J.M., Summers, L.H., 1991. Speculative dynamics. Rev. Econ. Stud. 58, 529-546.

Das, S., Gupta, R., Kanda, P.T., 2011. Bubbles in south african house prices and their impact on consumption. J. Real Estate Literature 19 (1), 71-91. Diba,

B.T., Grossman, H.I., 1988a. Explosive rational bubbles in stock prices? Am. Econ. Rev. 78, 520-530.

Diba, B.T., Grossman, H.I., 1988b. The theory of rational bubbles in stock prices. Econ. J. 98, 746-754.

Engle, R., Ito, T., Lin, W.L., 1990. Meteor showers or heat waves? Heteroskedastic intra-daily volatility in the foreign exchange market. Econometrica 58 (3), 525-542.

Evans, G.W., 1986. A test for speculative bubbles in the sterling-dollar exchange rate: 1981-84. Am. Econ. Rev. 76 (4), 621-636.

Evans, G.W., 1991. Pitfalls in testing for explosive bubbles in asset prices. Am. Econ. Rev. 81 (4), $922-930$.

Evans, M.D.D., 1996. Peso problems: their theoretical and empirical implications. In: Maddala, G.S., Rao, C.R. (Eds.), Handbook of Statistics. Statistical Methods in Finance, vol. 14. Elsevier Science Amsterdam, pp. 613-646.

Flood, P.F., Garber, P.M., 1984. Collapsing exchange rate regimes. J. Int. Econ. 17 (1-2), 1-13.

Flood, P.F., Hodrick, R.J., 1990. On testing for speculative bubbles. J. Econ. Perspect. 4 (2), 85-100.

Funke, M., Hall, S., Sola, M., 1994. Rational bubbles during Poland's hyperinflation: implications and empirical evidence. Eur. Econ. Rev. 38, $1257-1276$.

Gali, 2014. Monetary policy and rational asset price bubbles. Am. Econ. Rev. 104 (3), 721-752.

Greenwood, R., 2005. Short and arbitrage demand curves for stocks: theory and evidence on the dynamics of arbitrage. J. Financial Econ. 75, 607-649. Hall,

S.G., Psaradakis, Z., Sola, M., 1999. 'Detecting periodically collapsing bubbles: a markov-Switching unit root test'. J. Appl. Econometrics $14,143-154$.

Hamilton, J., Whiteman, C., 1985. The observable implications of self-fulfilling expectations. J. Monetary Econ. 16 (3), $353-373$.

Hamilton, J.D., 1988. Rational expectation econometric analysis of changes in regime. an investigation of the term structure of interest rates. J. Econ. Dyn. Control 12, 385-423.

Hamilton, J.D., 1989. A new approach to the economic analysis of nonstationary time series and the business cycle. Econometrica 57, 357-394. Hamilton, J., 1994. Time Series Analysis. Princeton University Press, NJ.

Hassan, S., 2013. 'South african capital markets: an overview'. South African Reserve Bank, pp. 04, Working Paper Series WP/13/.

Hausman, J.A., 1978. Speculation test in econometrics. Econometrica 46, 125-171.

Homm, U., Breitung, J., 2012. Testing for speculative bubbles in stock markets: a comparison of alternative methods. J. Financial Econometrics 10, $198-231$. Jordà, Ò., Schularick, M., Taylor, A.M., 2015. Leveraged bubbles, NBER Working Papers 21486.

Lucas, R.E., 1978. Asset prices in an exchange economy. Econometrica 46, 1429-1445.

Meese, R.A., 1986. Testing for bubbles in exchange markets: the case of sparkling rates. J. Political Econ. 94, $345-373$.

Mussa, M., 1984. The theory of exchange rate determination. In: Bilsen, J.F.O., Marsten, R.C. (Eds.), Exchange Rate Theory and Practice, NBER Conference Report. Chicago University Press, Chicago IL.

Nneji, O., Brooks, C., Ward, C., 2013. Intrinsic and rational speculative bubbles in the US housing market: 1960-2011. J. Real Estate Res. 35 (2), 121-152.

Phillips, P.C.B., Yu, J., 2011. 'Dating the timeline of financial bubbles during the subprime crisis'. Quantitative Econ. 2 (3), $455-491$.

Phillips, P.C.B., Wu, Y., Yu, J., 2011. Explosive behaviour in the 1990 nasdaq: when did exuberance escalate asset values? Int. Econ. Rev. 52 (1), 201-226.

Phillips, P.C.B., Shi, S., Yu, J., 2015. Testing for multiple bubbles: historical episodes of exuberance and collapse in the S\&P 500. Int. Econ. Rev. 56 (4), $1043-1077$.

Roche, M.J., 2001. The rise in house prices in Dublin: bubble, fad or just fundamentals. Econ. Model. 18 (2), $281-295$.

Schwert, G.W., 1989a. Business cycles, financial crisis and stock volatility. Carnegie-Rochester Conference Series on Public Policy 31, 83-126.

Schwert, G.W., 1989b. Why does stock market volatility change over time. J. Finance 44 (5), 1115-1153.

Shiller, R.J., 1981. Do stock prices move by two much to be justified by subsequent changes in dividends? Am. Econ. Rev. 71, 421-436.

Shiller, R.J., 2000. Irrational Exuberance, first edition. University Press, Princeton, N.J. Princeton.

Svensson, L., 2014. 'Inflation targeting and leaning against the wind'. Int. J. Cent. Bank. 10 (2), 103-114.

Van Norden, S., Schaller, H., 1993. The predictability of stock market regime: evidence from the Toronto stock exchange. Rev. Econ. Stat. 75 (3), 505-510.

Van Norden, S., 1996. Regime switching as a test for exchange rate bubbles. J. Appl. Econometrics 11, $219-251$.

West, K.D., 1987. A specification test for speculative bubbles? Q. J. Econ. 102, 553-580.

Zhang, Q., Sornette, D., Balcilar, M., Gupta, R., Ozdemir, Z.A., Yetkiner, H., 2016. LPPLS Bubble Indicators over Two Centuries of the S\&P 500 Index. In: Working Paper No. 201606. Department of Economics, University of Pretoria. 